\title{
INTERPRETASI TERHADAP SLOKA 40 KITAB SARASAMUSCAYA TENTANG VISI MISSI PANDITA MASA DEPAN
}

\author{
Oleh: I Made Girinata
}

\begin{abstract}
Pandita is someone who has gone through a dwijati or madiksa ceremony. Pandita duty is very important and absolute in Hinduism which even though it is difficult but Pandita duty is very noble and has moral obligations. In the face of increasingly complex developments, pandita should have credible abilities so they can compete with other religions. As the most important thing Pandita must still be able to maintain the value of her holiness by practicing the swadharma of dignity. Likewise, the community members, besides demanding that the purity of sulinggih be always maintained, should also be able to guarantee the lives and rights of Pandita / Sulinggih.
\end{abstract}

Keywords: Interpretation and Vision of Pandita's Mission for the Future.

\section{PENDAHULUAN}

Dewasa ini pada taraf kemajuan perkembangan pemikiran manusia masalah Pandita tak surut menjadi perhatian masyarakat umat terutama di kalangan intelektual dimungkinkan menjadikan Pandita sebagai ajang perdebatan. Bahkan pada belakangan ini mencuat fenomena tentang Pandita ikut terbawa pada pengklasifikasian suatu kelompok klen tertentu sehingga mempengaruhi kehidupan sosial kemasyarakatan yang berakibat pada kesenjangan dan kecemburuan sosial. Apalagi belakangan ini pertumbuhan pandita semakin pesat yang muncul dari semua klen yang ada. Dari pertumbuhan seperti ini tak pelak munculnya berbagai opini dalam masyarakat, seperti halnya tidak mengakui status pandita yang lainnya atau bahkan ada yang merasa lebih tinggi dari pandita klen yang lainnya.

Dipandang dari sudut proses penetapan seorang Pandita kini banyak menjadi pembicaran, karena dipandang tidak lagi sesuai dengan tradisi masa silam bahwa yang berhak menjadi Pandita adalah lahir dari keturunan seorang Pandita. Namun sekarang ada beberapa pandita yang lahir bukan dari keturunan pandita. Opini seperti ini menggejala di masyarakat karena sesuai dengan tradisi, bahwa keberadaan Pandita sangat erat kaitannya dengan sisya 
(hubungan guru dengan murid yaitu anggota masyarakat pendukung yang menobatkan dan juga yang akan mempergunakan jasanya setelah menjadi Pandita).

Di lain pihak ada kelompok-kelompok masyarakat utamanya golongan intelektual yang berdasarkan penilaiannya pada logika dan ratio, sehingga memandang legalitas pandita dari beberapa aspek seperti; kemampuannya, sikap sosialnya, kebersihannya dan sebagainya.

Sehingga fenomena seperti itu lebih bersifat pada penuntutan pada kewajiban agar pandita selalu dapat menjaga nilai kesucian dirinya, namun terkadang kita sebagai masyarakat sampai lupa akan hak-hak yang harus diterima oleh Pandita yang menjadi landasan utama bagi pandita untuk menjaga nilai kesucian dirinya. Fenomena yang tak dapat difungkiri bahwa kini lebih banyak warga masyarakat umat Hindu ketika mengadakan suatu yadnya jauh lebih memperhatikan nilai sosiologinya dengan mengutamakan anggaran pelayanan undangan, dibandingkan memberi pelayanan terhadap Pandita yang akan mendoakan atau memimpin upacara yadnya yang dilaksanakannya. Padahal sesungguhnya sebesar apapun yadnya itu bila tidak dipersembahkan oleh orang yang berhak untuk itu (Padita) serta didukung oleh perasaan tulus ikhlas dari yang beryadnya, maka yadnya itu tidak akan ada nilainya.

Atas dasar gejala seperti itulah tulisan kecil ini bertujuan untuk mengungkap tentang: apa dan siapa pandita itu, bagaimana kedudukan Pandita dalam masyarakat, dan bagaimana figur serta visi pandita yang cocok dimasa mendatang?

\section{PEMBAHASAN}

\subsection{Apa dan Siapa Pandita}

Kedudukan Pandita atau sering disebut dengan Sulinggih dalain kehidupan umat Hindu amat penting dan mutlak adanya. Bagi umat Hindu yang menaruh minat yang sungguhsungguh untuk meningkatkan diri menjadi Pandita patut disambut dan didukung dengan ketulusan hati yang suci. Dukangan dari semua pihak atas usaha itu penting sekali karena tangguurg jawab Pandita amat berat namun amat mulia.

Kata Pandita dalam bahasa Sanskerta berarti orang pandai, cendikiawan, bijaksana, sarjana, sujana. Pandita. Yang dimaksud dengan Pandita adalah seorang rohaniawan Hindu yang telah madwijati melalui upacara diksa Dwijati artinya lahir kedua kali. Pertama lahir atau dilahirkan oleh ibu-bapak (guru rupaka). Kedua dilahirkan pula dan diakui anak oleh seorang guru pengajian (nabhe). Sedangkan diksa adalah upacara penyucian seorang walaka untuk menjadi Pandita Upacara penyucian ini selain ritual ada juga ketentuan-ketentuan yang dikeluarkan oleh Parisada Hindu Dharma Indonesia.

$$
\text { Upacara diksa bukanlah sekedar }
$$
merupakan upacara perubahan status belaka dari seorang walaka menjadi Pandita. Namun di dalam proses upacara itu terkandung suatu 
makna yang mendalam mengenai hubungan batin antara guru Nabhe dengan sisyanya (calon diksita). Upacara diksa merupakan salah satu cara untuk meningkatkan diri dari fase kehidupan yang belum sempurna menuju kehidupan baru dalam dumia yang lebih sempurna.

Pada kenyataannya orang yang telah didwijati diberikan berbagai sebutan tergantung pada ketentuan keluarga dan wangsanya Ada yang disebut Pedanda, Rsi, Bhagawan, Bhujangga, Empu dan Dukuh. Semua dwijati itu memiliki kedudukan sejajar dalam pandangan agama Hindu. Keseluruhannya tennasuk Pandita karena semua gelar dwijati itu baru boleh dipakai setelah melalui proses upacara diksa Dalam Yajur Veda XX,25 diuraikan tentang diksa itu sebagai berikut :

\section{Dengan melaksanakan brata seseorang memperoleh diksa,}

Dengan melakukan diksa seseorang memperoleh daksina,

\section{Dengan daksina seseorang melaksanakan sradha,}

Dan dengan sradha seseorang memperoleh satya.

Brata adalah suatu janji diri untuk melaksanakan pantangan-pantangan keagamaan agar mendapat kesucian rohani. Diksa artinya telah memperoleh kesucian atau dwijati. Daksina adalah pendapatan yang suci karena didapatkan dari perbuatan suci dan terhormat. Sradha artinya keyakinan atau keikhlasan untuk mengabdi pada Ida Sang Hyang Widhi. Satya adalah kebenaran yang tertinggi.

Upacara diksa merupakan pernyataan klimaks bagi seseorang untuk dapat secara resmi dinyatakan sebagai pandita. Namun sebelum itu seseorang yang akan menjadi pandita sungguh sangat mempersiapkan diri baik lahir maupun bathin baik formal maupun non formal karena pada nantinya akan mengemban tugas kewajiban moral. Secara formal sudah diatur oleh lembaga Parisada dengan persyaratan cukup ketat serta melalui suatu proses pendidikan, namun secara non formal terasa lebih berat lagi, karena menyangkut masalah pengendalian indriya pribadi calon pandita Bahkan pada nantinya akan terus diaplikasikannya selama menjadi pandita seperti melaksanakan ajaran Panca Yama Brata (Ahimsa adalah tidak membunuh, Brahmacari adalah belajar, Satya adalah setia pada kebenaran, Awyawaharika adalah tidak suka bertengkar dan Asteya adalah tidak mencuri). Di samping itu harus dapat melaksanakan ajaran Panca Niyama Brata, ajaran Dasa Sila, ajaran Catur Paramita, ajaran Tri Kaya Parisudha dan sebagainya

Selain itu ada beberapa pantangan yang harus ditaati dalam hal makan dan minum oleh seorang Pandita yakni: tidak boleh makan daging babi piaraan, makan daging ayam, anjing, tikus, ular, kucing, harimau, rase, kera, tupai, kadal, binatang yang berkuku satu dan berjari lima Yang paling tidak boleh dimakan adalah burung hantu, burung elang, gagak, jalak, kakatua, bangau, termasuk tidak boleh makan sisa-sisa makanan dari orang lain. 
Jadi dari uraian diatas dapat disimpulkan bahnwa Pandita adalah orang bijaksana dan suci dalam agama Hindu yang telah melalui suatu proses upacara dwijati atau diksa yang sebelumnya diperoleh melalui suatu perjuangan moral yang sangat ketat.

\subsection{Kedudukan Pandita (Sulinggih)}

Seseorang yang telah madiksa diberi kedudukan sebagai seorang Sulinggih di masyarakat atau sekarang disebut dengan Pandita. Su artinya utama atau mulia dan linggih artinya kedudukan. Sulinggih artinya mendapat kedudukan yang utama atau mulia di masyarakat. Masyarakat umat Hindu sepatutnya sangat menghormati seorang Pandita (Sulinggih), karena ia telah mencapai kesucian diri lahir-bathin melalui upacara dwijati dan kemanusiannnya tidak lagi berstatus walaka.

Upacara diksa selain bertujuan meningkatkan kesucian diri guna mencapai tingkatan dwijati, namun juga mempunyai nilai sosiologis, dimana sang diksita berubah status sosialnya di dalam masyarakat umat Hindu yaitu diberi nama abhiseka dari walaka menjadi sadakha yang disebut amari-aran, berubah penampilan serta atribut yang disebut amari wesa dan merubah aktivitas kehidupan yang disebut amari-wisaya. Perubahan jati diri itu menyebabkan perubahan sikap, pandangan dan prilaku masyarakat terhadapnya, sebagai suatu konsekwensi logis daripada pengakuan dan penghargaan masyarakat terhadap kedudukan Sulinggih.
Atas dasar itu dan juga atas penghormatan terhadap sesana kawikon yang harus ditaati oleh sulinggih, maka seorang sulinggih atau wiku dibebaskan dari tugas dan kewajiban sosial di masyarakat seperti : ayahan banjar, ayahan desa, dan pekerjaan-pekerjan lain yang bersifat pisik dan kemasyarakatan. Selain itu seorang sulinggih mendapat kedudukan yang tersendiri di dalam masyarakat seperti tidak kena cuntaka (kecuali wiku wanita yang sedang mengalami menstruasi) dan beliau juga tidak nyuntakaian atau menjadikan cuntaka (kotor secara rohani). Seorang sulinggih atan pandita bila lebar (wafat), menurut tradisi dan sastra jenasahnya boleh dibakar di luar setra seperti di tegalan, sawah, karena beliau tidak kena cuntaka dan juga tidak nyuntakain (menyebabkan cuntaka). Hal itu disebabkan karena pandita atau sulinggih adalah orang sudah tergolong suci lahir-bathin. Untuk itu beliau juga wajib menjaga agar dirinya selalu suci antara lain dengan melakukan puja parikrama setiap hari dan juga melakukan yoga samadhi serta teguh melaksanakan tapa brata

Kedudukan pandita atau sulinggih yang demikian itu adalah telah melembaga di masyarakat yang keadaannya telah mantap dari dahulu kala dan berlanjut terus sebagai warisan tatanan hidup umat Hindu. Hal itu patut dipahami oleh umat Hindu sebagai suatu dharma negara dan dharma agama. Memahami hal itu akhirnya masyarakat dituntut suatu sikap hormat dan memberikan suatu perlakuan yang patut dan benar terhadap Pandita (Sulinggih). Dengan kata lain ada seperangkat tata krama yang berlaku bagi pandita. Tata krama itu 
haruslah ditegakkan di dalam masyarakat. Jika tidak demikian, maka tata-titi atau tata kemasyarakatan dan tata keagaman umat Hindu akan memudar. Pudarnya tata kemasyarakatan akan dapat menyebabkan tidak tertibnya kehidupan masyarakat. Demikian pula pudarnya tata keagamaan akan mendorong munculnya suatu sekularisme dan profanisasi dalam agama munculnya sekularisme dan profanisasi dalam agama adalah merupakan suatu titik awal daripada pudarnya kehidupan agama itu sendiri. Demikian juga sebaliknya bukan masyarakat umat saja yang mesti dituntut menegakkan tata kemasyarakatan dan tata keagamaan dalam konteks hubungan umat dengan Pandita (Sulinggih), melainkan terhadap diri Pandita (Sulinggih) sendiri dituntut suatu keteguhannya melaksanakan dharmaning kawikon dan taat terhadap sesana kawikon serta menerapkan dasa dharma kapanditaan. Sesana harus ditaati dan jangan sekali-sekali Pandita (Sulinggih) melanggar sesananya, karena akan berakibat fatal terutama bagi dirinya (asing angelung sasana angewewaken sanghara bhumi).

\section{FIGUR SERTA VISI PANDITA DIMASA MENDATANG}

Sebagaimana diketahui bahwa setiap agama yang ada di Indonesia mempunyai orangorang suci. Diyakini karena orang suci mampu dan punya kewenangan untuk memimpin umat dan memimpin suatu upacara (ritual). Pada sisi kehidupannya yang lain orang suci juga bertugas untuk membina kehidupan umat beragama. Dilihat dari fungsi seorang pandita, dikalangan umat Hindu khususnya di Bali ada kekeliruan persepsi mengenai fungsi sesungguhnya bagi pandita atau sulinggih. Ada anggapan bahwa pandita dipandang sebagai pemimpin upacara yadnya atau muput karya semata-mata. Demikian pula ngalokapalasraya itu diartikan muput karya saja. Persepsi yang keliru itu (misunderstanding) terdapat baik dikalangan umat Hindu manpun di kalangan pandita itu sendiri. Dilandasi oleh persepsi yang keliru itu, seolah-olah tujuan dari ,adiksa adalah hanya untuk muput karya belaka, sehingga orientasi pandita terutama dipusatkan ke arah memimpin jalannya upacara yadnya. Sudah tentu orientasi yang sempit ini tidak sesuai dengan dharmaning kawikon.

Fenomena seperti itu tidak bisa kita salahkan begitu saja, karena kebanyakan warga masyarakat umat berusaha untuk tidak mau mengetahui apa sesungguhnya tugas dari pandita itu, melainkan hanya sebagai pelanjut tradisi secara fanatik. Disisi yang lain ada kemungkinan dari pandita itu sendiri yang mengetahui hakekat pokok dari tugasnya sehingga demi menjaga nilai kesuciannya akhirnya tidak mensosialisasikannya kepada umat. Atau barangkali karena ada unsur politis demi menjaga kehormatan keluarga sehingga hal-hal yang akan merugikan atau yang merongrong kewibawaan keluarga tidak disosialisasikan atau sengaja dirahasiakan. Hal itu sampai sekarang dapat kita buktikan masih ada tradisi-tradisi yang dianut secara fanatik. Misalnya, dulu pada jamannya orang yang hanya boleh madiksa menjadi pandita adalah dari kelompok Brahmana Wangsa yang dipandang 
sebagai kelompok paling tinggi di antara semua umat yang setelah didiksa diberi gelar Pedanda/ Pranda. Namun dijaman era globalisasi ini dalam meningkatnya taraf intelektual umat, semua istilah-istilah seperti pedanda, sulinggih, pandita dikatagorikan sebagai seorang Brahmaura yang dapat dicapai oleh setiap orang apabila persyaratan spiritual dan material telah dipenuhi. Bahkan sesuai dengan hasil Mahasabha VIII dipertegas bahwa setiap umat yang telah melalui proses upacara madiksa digolongkan sebagai seorang Brahmana dengan memberikan gelar yang sama yaitu "Pandita". Pernyataan seperti itu mengandung suatu makna bahwa semua umat manusia pada dasarnya adalah sama yang hanya dibedakan oleh faktor guna atau kelahiran.

Sekarang dijaman globalisasi pada taraf pemikiran manusia yang semakin melek dan kompleks dengan lebih menekankan pada bidang intelektual, masalah pandita menjadi obyek perhatian dan pembicaraan yang sangat serius. Sehingga muncul dualisme pandangan, disatu sisi masyarakat umat masih mutlak mengikuti tradisi lama sehingga lebih bersifat ortodoks termasuk bahwa seseorang menjadi pandita harus dari keturunan pandita, karena dilandasi dengan sisya sebagai pendukung dan disi lain utamanya golongan intelektual berdasarkan pada pengalaman dan analisanya berupaya meninggalkan tradisi-tradisi yang sudah tidak sesuai konsep asli sehingga dipandang tidak cocok untuk jaman sekarang. Kelompok semacam ini lebih menekankan pada penganalisaan secara logika, seperti misalnya : dibidang kebersihan, kemampuan (kredibilitas), bahkan berdalih menuju pada Hindu modernis dengan mengakui semua pandita dari klain manapun. Karena landasannya bahwa setiap orang atau siapapun orangnya yang telah melalui proses upacara madiksa dianggap Brahmana yaitu disebut Pandita Sehingga dari kenyataan itu dimungkinkan masyarakat bisa menggunakan pandita manapun sesuai dengan hati nurani.

Maka dari itu mengacu pada kenyataan diatas, sangat perlu kiranya untuk kedepan kita memiliki figur pandita yang mampu menjawab masalah-masalah diatas, tidak tampil dengan penuh ciri keklasikan melainkan mampu tampil sesuai dengan jamannya. Untuk mendapatkan semua itu sangat perlu kiranya kejelasan tentang visi daripada panditauntukmasa depan.

Berbicara tentang figur serta visi pandita kita tidak bisa lepas dari fungsi yang paling mendasar dari seorang pandita. Untuk itu akan diuraikan satu kutipan dari kitab Sarasamuscaya 40 berikut :

"Kunang kengetakena, sasing kajar de sang hyang cruti, dharma ngaranika sakajar de sang hyang smrti kuneng, dharma ta ngaranika,cistacara kunang, acaranika sang cista, dharma ta ngaranika, cista ngaran sang hyang satyawadi, sang apta, sang patirthan, sang panadahan upadeca sangksepa ika katiga, dharma ngaranira. 
"Maka yang patut diingat adalah, segala apa yang diajarkan oleh sruti, disebut dharma, semua yang diajarkan smrti, pun dharma pula namanya itu, demikian pula tingkah laku sang sista, disebut juga dharma, sista artinya orang yang berkata jujur yang setia pada kata-katanya, orang yang dapata dipercaya, orang yang menjadi tempat pensucian diri, orang yang memberikan ajaran-ajaran atau nasehat-nasehat, seingkatnya ketigatiganya itu disebut dharma.

Kutipan di atas menunjukkan bahwa, ada empat landasan pokok dari fungsi pandita sebagai perbuatan dharma yang harus dipahami seperti : 1. Sang Satyavadi yaitu berkata, berpikir, dan berbuat yang jujur. 2. Sang Apta yaitu kemampuan yang harus dimiliki oleh pandita 3 . Sang Patirthan yang melaksanakan kewajiban melaksanakan penyucian baik bhuwana alit maupun bhuwana agung. 4. Sang Panadahan Upadesa yaitu mampu memberikan keterangan kepada masyarakat dengan nasehat, arahan dan didikan. Maka dari itu menyangkut harapan kita tentang visi pandita kedepan, hendaknya mampu memahami serta melaksanakan keempat landasan pokok di atas dengan benar dan tidak merasakan sebagai suatu beban. Untuk menyikapi empat ajaran itu oleh seorang pandita, maka di bawah ini akan di paparkan beberapa solusi pada masing ajaran yakni :

\subsection{Pandita sebagai sang Satyavadi}

berbuat yang jujur dan benar. Kebenaran dalaun hal ini adalah kebenaran menurut Veda Pandita tidak boleh berbicara menyimpang dengan kebenaran Veda walaupun mungkin dirasakan pahit dan akibatnya secara material tidak menguntungkan. Pandita tidak boleh berbicara hanya dengan pertimbangan kebenaran logika dan hukum semata Ada rasa keadilan yang harus diperhatikan, ada ajaran Veda yang harus dipakai pedoman. Jangan sampai pandita punya pikiran komersial sehingga menghalalkan segala cara seperti menetapkan upacara tidak sesuai dengan petunjuk dengan rnaksud warga masyarakat yang beryadnya tidak beralih pada pandita lain.

\subsection{Pandita sebagai Sang Apta}

Maksudnya adalah seorang pandita dimasa datang hendaknya memiliki kemampuan yang memadai (kredible). Kemampuan dimaksud bahwa pandita di samping ngalokapalasraya, hendaknya memiliki wawasan yang luas dalam bidang keagamaan agar mampu tampil seimbang dengan agama lain terutama dimasa mendatamg yang semakin kompleks. Pandita hendaknya punya kemampuan dalam biding berargumentasi.

\subsection{Pandita Sebagai Sang Patirthan}

Sang Patirthan dimaksudkan bahwa pandita dipandang oleh warga masyarakat umat sebagai tempat untuk melaksanakan pensucian baik lahir maupun bathin. Sebagai 
tempat pensucian, hendaknya pandita dapat secara ikhlas melayani umat sesuai dengan pengakuan masalahnya dengan tidak melihat derajat serta klasifikasi seseorang. Sebab dalam tugas sebagai pensucian, pandita akan lebih banyak berhadapan dengan orang yanag ditimpa kesusahan.

\subsection{Pandita Sebagai Sang Panadahan Upadesa}

Panadahan Upadesa maksudnya dimana pandita diharapkan mampu memberikan ketentraman kepada masyarakat dengan nasehat, arahan dan pendidikan. Dalam hal ini pandita hendaknya tidak sampai tidak melayani warga masyarakat umat tatkala ada yang datang minta nasehat, bimbingan, serta pengetahuan tentang keagamaan. Sebab masih banyaknya dijumpai pandita-pandita yang tidak bersedia atau pelit ketika ditanya pengetahuan agama dengan alasan pingit atau aywawera.

\section{SIMPULAN}

Dari uraian singkat di atas menyangkut tentang visi pandita di masa mendatang dapat disimpulkan bahwa: Pandita adalah seseorang yang telah melalui upacara dwijati atau madiksa. Tugas pandita sangat penting dan mutlak dalam agama Hindu yang sekalipun susah namun tugas pandita adalah sangat mulia serta punya kewajiban moral. Dalam menghadapi perkembangan yang semakin kompleks, hendaknya pandita mempunyai kemampuan yang kredible sehingga mampu bersaing dengan agama lain. Sebagai hal yang paling penting Pandita harus tetap dapat menjaga nilai kesucian dirinya dengan menjalankan swadharma kepanditaan. Demikian juga warga masyarakat disamping menuntut selalu terjaganya kesucian sulinggih, hendaknya harus juga dapat menjamin kehidupan dan hak-hak Pandita/Sulinggih.

\section{Daftar Pustaka}

Pudja, Gde. 1999. Bhagawad Gita: Pancama Veda. Surabaya: Paramita.

Pudja, Gde. 2007. Weda Parikrama: Himpunan Naskah Mantra dan Stotra. Surabaya: Paramita.

Pudja, Gde dan Tjokorda Rai Sudharta. 2004. Manawa Dharmasastra. Surabaya: Paramita.

Putra, Ida Bagus Rai. Dkk. 2013. Swastikarana: Pedoman Ajaran Hindu Dharma. Jakarta: PHDI Pusat

Radhakrishnan, S. 2008. Upanisad-Upanisad Utama. Surabaya: Paramita.

Suhardana, K.M. 2006a. Dasar-dasar Kepemangkuan Suatu Pengantar dan Bahan Kajian Bagi generasi mendatang. Surabaya: Paramita.

Suhardana, K.M. 2006b. Pengantar Beberatan Pemangku: Bahan kajian untuk 
pengendalian diri. Surabaya: Paramita.

Suhardana, K.M. 2008. Dasar-Dasar Kesulinggihan Suatu Pengantar Bagi Sisya Calon Sulinggih. Surabaya: Paramita. 